\title{
Groundwater Nitrate Removal Performance of Selected Pseudomonas Strains Carrying nosZ Gene in Aerobic Granular Sequential Batch Reactors
}

\author{
Miguel Hurtado-Martinez ${ }^{1}\left(\mathbb{D}\right.$, Barbara Muñoz-Palazon ${ }^{1,2, *} \mathbb{C}$, Alejandro Gonzalez-Martinez ${ }^{1,2}$, \\ Maximino Manzanera ${ }^{1,2}$ (D) and Jesus Gonzalez-Lopez ${ }^{1,2}$ \\ 1 Institute of Water Research, University of Granada, C/Ramón y Cajal, 4, 18071 Granada, Spain; \\ miguelhm@ugr.es (M.H.-M.); agon@ugr.es (A.G.-M.); manzanera@ugr.es (M.M.); jgl@ugr.es (J.G.-L.) \\ 2 Faculty of Pharmacy, University of Granada, Campus de Cartuja, s/n, 18071 Granada, Spain \\ * Correspondence: bmp@ugr.es
}

\section{check for}

updates

Citation: Hurtado-Martinez, M.; Muñoz-Palazon, B.; Gonzalez-

Martinez, A.; Manzanera, M.;

Gonzalez-Lopez, J. Groundwater

Nitrate Removal Performance of

Selected Pseudomonas Strains

Carrying nosZ Gene in Aerobic

Granular Sequential Batch Reactors.

Water 2021, 13, 1119. https: / /

doi.org/10.3390/w13081119

Academic Editor: Paolo Fabbri

Received: 17 March 2021

Accepted: 16 April 2021

Published: 19 April 2021

Publisher's Note: MDPI stays neutral with regard to jurisdictional claims in published maps and institutional affiliations.

Copyright: (c) 2021 by the authors. Licensee MDPI, Basel, Switzerland. This article is an open access article distributed under the terms and conditions of the Creative Commons Attribution (CC BY) license (https:// creativecommons.org/licenses/by/ $4.0 /)$.

\begin{abstract}
Four granular sequencing batch reactors (GSBRs) were inoculated with four denitrifying Pseudomonas strains carrying nosZ to study the process of granule formation, the operational conditions of the bioreactors, and the carbon concentration needed for nitrate removal. The selected Pseudomonas strains were P. stutzeri I1, P. fluorescens 376, P. denitrificans Z1, and P. fluorescens PSC26, previously reported as denitrifying microorganisms carrying the nos $Z$ gene. Pseudomonas denitrificans Z1 produced fluffy, low-density granules, with a decantation speed below $10 \mathrm{~m} \mathrm{~h}^{-1}$. However, P. fluorescens PSC26, P. stutzeri I1, and P. fluorescens 376 formed stable granules, with mean size from 7 to $15 \mathrm{~mm}$, related to the strain and carbon concentration. P. stutzeri I1 and P. fluorescens 376 removed nitrate efficiently with a ratio in the range of $96 \%$, depending on the source and concentration of organic matter. Therefore, the findings suggest that the inoculation of GSBR systems with denitrifying strains of Pseudomonas spp. containing the nosZ gene enables the formation of stable granules, the efficient removal of nitrate, and the transformation of nitrate into nitrogen gas, a result of considerable environmental interest to avoid the generation of nitrous oxide.
\end{abstract}

Keywords: Pseudomonas; granular biomass; sequential batch reactor; nitrate-polluted groundwater; heterotrophic denitrification

\section{Introduction}

Nowadays, a large proportion of the world's population uses groundwater as a drinking water resource, so the quality of groundwater and the removal of any pollutants is of paramount importance worldwide. The increase in the use of chemical compounds such as fertilizers, pesticides, pharmaceuticals, and personal care products is responsible for extensive groundwater pollution. Nitrate is one of the most widespread pollutants in groundwater due to the intensive use of fertilizers in agriculture, resulting in the joint release of nitrate and phosphate ions [1]. Excess nitrate can be released to aquatic environments because it is highly soluble and mobile, which affects the quality of water [2].

Some diseases, such as methemoglobinemia, thyroid disease, or neural tube defects, have been linked to the consumption of drinking water contaminated with nitrate [3]. Nitrite has been described as a carcinogenic agent [4,5]. Moreover, Brender et al. [6] demonstrated that high concentrations of nitrate could be associated with congenital malformations such as cleft palate, cleft lip, and deformities of the arm.

For these reasons, the European Water Framework [7] established the maximum nitrate concentration of $50 \mathrm{mg} \cdot \mathrm{L}^{-1}$ for drinking water, even though the recommended nitrate concentration for drinking water is below $25 \mathrm{mg} \cdot \mathrm{L}^{-1}$, assuming this value for high-quality drinking water. The areas most affected by nitrate pollution are designated as nitrate vulnerable zones and are subject to the mandatory Code of Good Agricultural 
Practice [8]. The results of compliance with this directive have been reflected in the trends in nitrate levels in some countries, such as the northern regions of Europe [5], while the Mediterranean countries have experienced major difficulties in achieving the quality standard due to the strong pressure linked with intensive agriculture [3]. To exemplify this difficulty, in 2012, 108 Spanish municipalities reported having an average of $3.5 \mathrm{mg} \cdot \mathrm{L}^{-1}$ $\mathrm{NO}_{3}$ in the groundwater they used as a source of drinking water, with a concentration range of 0.4 to $66.8 \mathrm{mg} \cdot \mathrm{L}^{-1}$ [9].

Given this background, the sanitary control of groundwater has become of special interest for governments. Therefore, in order to achieve the standard, several physical, chemical, and biological groundwater treatment technologies have been developed, amongst which we may highlight systems such as chemical reduction [10], electrodialysis [11], ion exchange [12], adsorption [13], reverse osmosis [14], biofilters [15], and aerobic granular technology [3]. Although ion exchange is a widely implemented technology for treating nitrate, when the resin is exhausted, the brine waste has negative environmental impacts [12]. Reverse osmosis and electrodialysis systems have high initial and operational costs, which are translated into high economic and energy requirements [16], restricting their implementation in small populations.

Biological water treatment systems could be considered in general terms as environmentally friendly and cost-effective technologies because the processes are carried out by heterotrophic or autotrophic microorganisms. However, biological technologies could also present some problems derived from their operating conditions and the start-up or maintenance period of the bioreactors [17]. Several biological wastewater technologies have been developed using diverse strategies to reach a successful nitrate removal ratio, for instance, using external carbon sources in anoxic reactors [18]. For drinking water treatment, several technologies have been designed: some of them are autotrophic technologies such as sulfurand hydrogen-based denitrification processes, others are heterotrophic technologies. The most widely implemented technologies use biofilters, membrane bioreactors, fluidized bed reactors, amongst others. These technologies provide advantages compared with physical or chemical technologies, mainly in terms of the economic and energetic aspects. However, the high hydraulic retention time directly affects the volume of groundwater treated and poses difficulties for cleaning the system, which can increase investment costs [15]. For these reasons, new low-cost and environmentally friendly technologies are gaining relevance, and in this context, a novel aerobic granular technology for treating nitrate-polluted groundwater was recently described [3].

Granules formed in the granular sequencing batch reactor (GSBR) system have a concentric structure of several layers, with different microbial populations between the layers; due to the restricted diffusion of oxygen and nutrients through the granule, the aerobic, anoxic, and anaerobic zones can be defined [19]. Aerobic microorganisms, such as ordinary heterotrophic organisms (OHOs), ammonium-oxidizing bacteria (AOBs), and nitrite-oxidizing bacteria (NOBs), grow in the outer layer of the granule. Polyphosphateaccumulating organisms (PAOs) and glycogen-accumulating organisms (GAOs) are located in the interlayer, and denitrifying microorganisms in the deeper layer of the granule [20]. Thus, granular microorganisms generate a constant gradient of nutrients used during the oxidation and reduction processes, allowing GSBR technology to completely eliminate organic matter, nitrogen, and phosphorus in a single reactor [19].

The granular conformation is promoted by the circular and continuous motion produced in the sequential batch reactor (SBR). In addition, the production and content of extracellular polymeric substances accumulated in the microbial surface encourages attachment between cells [21]. The EPS promote the morphological structure, suggesting the role of EPS is key during the conformation of microbial aggregates and also in steady-state because it immobilizes the cells without any supporting material [22]. The system is based on the metabolism of different microorganisms, including denitrifying bacteria and specifically Pseudomonas strains, which may present the nosZ gene in their genomes. Nitrous oxide reductase is coded by the nos $Z$ gene, and catalyzes the conversion of nitrous oxide 
$\left(\mathrm{N}_{2} \mathrm{O}\right)$ to dinitrogen gas $\left(\mathrm{N}_{2}\right)$ [22]. However, many denitrifying bacteria lack this enzyme, and when the denitrification process is performed by these nosZ-deficient bacteria, the nitrate is transformed into $\mathrm{N}_{2} \mathrm{O}$ gas [23], which is well-known to be a potent greenhouse gas [24]. For instance, Acidovorax facilis, Citrobacter diversus, and Enterobacter agglomerans are only able to reduce $\mathrm{NO}_{3}$ to $\mathrm{NO}_{2}$, without further reduction of $\mathrm{NO}_{2}$ to $\mathrm{N}_{2}$ and cause greenhouse gas production [25]. Consequently, the removal of $\mathrm{NO}$ and $\mathrm{N}_{2} \mathrm{O}$ in aerobic granular systems represents an additional advantage of this type of technology.

The main goal of this research was to optimize GSBR bioreactors at the laboratory scale using cultures of denitrifying strains of Pseudomonas carrying the nos $Z$ gene as inocula to treat nitrate-polluted groundwater. To achieve this goal, the best operating conditions for each strain to form stable granules, nitrate removal capacity using different carbon sources, and the most appropriate $\mathrm{C}: \mathrm{N}$ ratio to successfully remove nitrate were studied in order to obtain high-quality effluent that can be considered suitable for human consumption. Then, the knowledge of the denitrification process on aerobic granules using Pseudomonas culture would allow the implementation of GSBRs for contaminated groundwater treatment.

\section{Materials and Methods}

\subsection{Design and Operating Conditions}

Four sequential batch bioreactors were started using, as inoculum, $1 \mathrm{~L}$ of liquid (TSB medium) culture of four denitrifying strains of Pseudomonas, in which the presence of the nosZ gene had previously been identified: P. stutzeri var. mendocina (1I) and P. fluorescens PSC26 were provided by the Zaidin Experimental Station (CSIC-Granada), P. fluorescens 376 was provided by the Water Research Institute Culture Collection (University of Granada), and P. denitrificans Z1 was supplied by the National Collection of Industrial, Food, and Marine Bacteria (NCIMB) (NC012776) [26-28]. The bioreactor configuration was designed to be $50 \mathrm{~cm}$ long and $9 \mathrm{~cm}$ in diameter, with an operational volume of $2.5 \mathrm{~L}$ (Figure 1). The air flow $\left(3.0 \mathrm{~L} \cdot \mathrm{min}^{-1}\right)$ was supplied by fine bubbles at the bottom of the bioreactors through a spargers plate. The temperature was controlled to $25^{\circ} \mathrm{C}$. The dissolved oxygen and $\mathrm{pH}$ were monitored as $4.2 \pm 0.4 \mathrm{mg} \mathrm{O}_{2} \mathrm{~L}^{-1}$ and $7.4 \pm 0.1$, respectively, five times a week, using Crison probes.

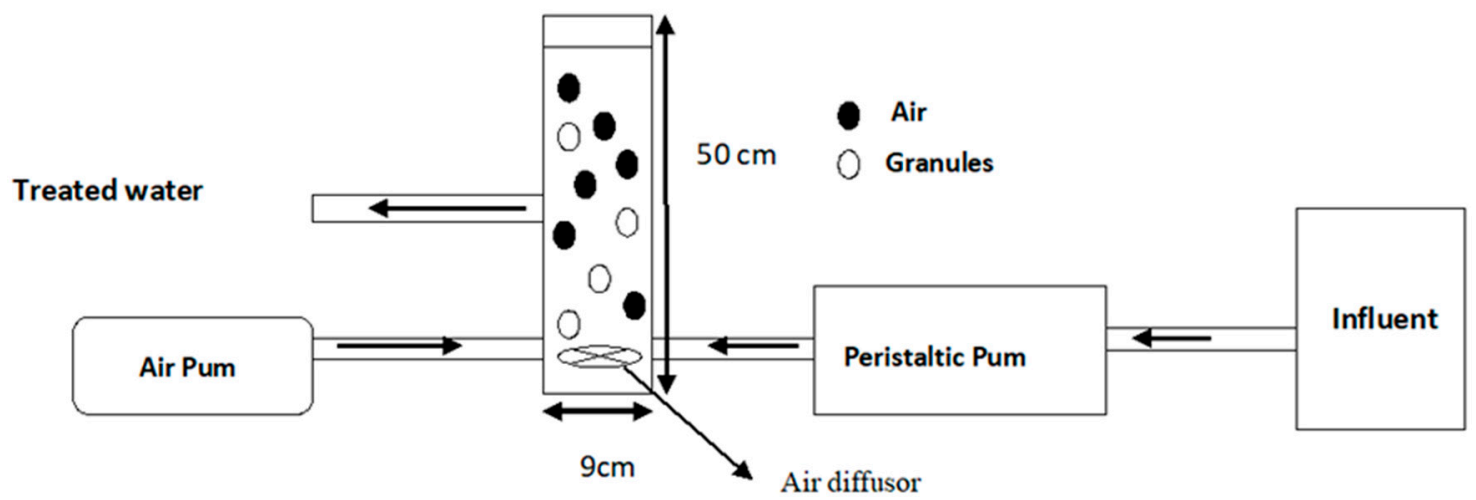

Figure 1. Schematic diagram of a sequencing batch bioreactor inoculated with cultures of denitrifying Pseudomonas strains.

Two types of experiment were set up in the sequential batch bioreactors. For the first experiment, the different bacterial strains were tested for the formation of granules using sodium acetate as the only carbon source. For the second experiment, two carbon sources (sodium acetate and methanol) were tested using the bacterial strains that formed granules (P. stutzeri PSC26 and P. fluorescens 376). The GSBR systems fed with sodium acetate were both operated for 180 days. In the case of Pseudomonas denitrificans, the bioreactor was operated for 30 days using sodium acetate because this strain was not able to form granules. For P. stutzeri PSC26 and P. fluorescens 376, which were fed with methanol as carbon source, the bioreactors were operated for 180 days. 
The chemical composition of the synthetic groundwater used to feed the pilot plants consisted of mineral salts and a single source of carbon (sodium acetate in the first experiment or methanol in the second experiment). The mineral salts per liter of distilled water comprised $0.1 \mathrm{~g}$ $\mathrm{MgSO}_{4} \cdot 7 \mathrm{H}_{2} \mathrm{O}, 0.085 \mathrm{~g} \mathrm{~K}_{2} \mathrm{HPO}_{4}, 0.04 \mathrm{~g} \mathrm{KCl}$, and $0.03 \mathrm{~g} \mathrm{KH}_{2} \mathrm{PO}_{4}$. Different C:N (carbon/nitrogen) ratios were tested (Table 1) using acetate or methanol, with the aim of establishing the relationship most suitable for the granulation process and the nitrate removal capacity [29].

Table 1. Carbon (sodium acetate and methanol) and nitrate concentrations added to the synthetic groundwater used to feed aerobic granular pilot plants inoculated with denitrifying Pseudomonas strains.

\begin{tabular}{cccc}
\hline Operational Day & Sodium Acetate & $\begin{array}{c}\text { Sodium Nitrate } \\
\left(\mathbf{m g} \cdot \mathbf{L}^{-\mathbf{1}} \mathbf{)}\right.\end{array}$ & Methanol \\
\hline $\mathbf{0 - 3 0}$ & 900 & 127 & 300 \\
$\mathbf{3 1 - 6 0}$ & 400 & 127 & 300 \\
$\mathbf{6 1 - 9 0}$ & 300 & 100 & 300 \\
$\mathbf{9 1 - 1 8 0}$ & 200 & 100 & 200 \\
\hline
\end{tabular}

The sequential batch reactors cycle had a hydraulic retention time of $10 \mathrm{~h}$, and the exchange volume was $60 \%$ of the operational volume reactor in each cycle. The stages consisted of: aeration $446 \mathrm{~min}$, settling velocity $3 \mathrm{~min}$, wash-out of $20 \mathrm{~min}$, and feeding period $10 \mathrm{~min}$. During the start-up phase, the settling time of the system decreased, so the settling time was established at 10 min during the first seven days of operation, whereas for days 8-14 of operation, the settling time was adjusted to $5 \mathrm{~min}$. Finally, after day 15 of operation, the bioreactors were adjusted to $3 \mathrm{~min}$ of settling time to favor the development of the granular biomass [30].

\subsection{Physical Determination}

The granulation process and the stability of the systems were analyzed twice per week. Mean granule size was measured using representative samples during the aeration stage $(n=25)$ from each reactor. Measurements were taken using a millimeter scale observed by stereoscopic microscope. The settling velocity of the granules was also measured following the protocol described by Laguna et al. [31], slightly modified, using a $2 \mathrm{~m}$ glass column with a manual chronometer.

\subsection{Chemical Determination}

Duplicate samples from the influent and effluent were taken four times a week in order to evaluate the removal ratio performance. Chemical oxygen demand (COD) was measured following the standard spectrophotometric method described by APHA [32]. Biological oxygen demand at day $5\left(\mathrm{BOD}_{5}\right)$ was also measured using dark bottles and an OxiTop ${ }^{\mathrm{TM}}$ [3].

Effluent and influent samples were taken periodically from each of the reactors for the determination of nitrite and nitrate concentration. This determination was performed by ion chromatography (Metrohm) according to Gonzalez-Martinez et al. [33] with a Metrosep A Supp 4-250 anion column. A carbonate/bicarbonate solution was used as the eluent. Calibration curves for the ion chromatography were created at the beginning of each analysis.

\subsection{Mass Balance of Pollutants for All Bioreactors during the Operational Period}

Physicochemical performance data were used to calculate the amounts of daily contaminants processed by each bioreactor, which were inoculated with different denitrifying Pseudomonas strains in order to identify the system with the lowest carbon footprint and the most sustainable strain to develop the transformation into $\mathrm{N}_{2}$ by denitrification and the carbon load.

For calculation of the mass balance of nitrogen, total nitrogen entering into the bioreactors, which was in the form of nitrate, was controlled; it was converted either into nitrite $\left(\mathrm{NO}_{2}{ }^{-}\right)$or nitrogenous gases $\left(\mathrm{NO}, \mathrm{N}_{2} \mathrm{O}\right.$, and $\left.\mathrm{N}_{2}\right)$. The equations employed for these determinations were previously described by Rodriguez-Sanchez et al. [34]: 
Qin TNin $=$ Qout TNout + Nous gas

Qin $\left(\mathrm{NH}_{4}{ }^{+}-\mathrm{Nin}+\mathrm{NO}_{\mathrm{x}}-\mathrm{Nin}\right)=$ Qout $\left(\mathrm{NH}_{4}{ }^{+}-\mathrm{Nout}+\mathrm{NO}_{\mathrm{x}}-\mathrm{Nout}\right)+$ Nous gas

\section{Results and Discussion}

\subsection{Granulation Processes and Bioreactor Start-Up}

After the aerobic granular bioreactors were inoculated with the four selected denitrifying strains of Pseudomonas containing the nos $Z$ gene, the granulation process was studied for the three strains between operational days 5 and 40 (Figure 2). Pseudomonas denitrificans strain Z1, instead of forming granules, produced floccular structures with a filamentous and irregular surface. Pseudomonas denitrificans was able to form a granular morphology but the granules were fluffy and irregular, with a rough surface. For this reason, given the low density and lack of compactness of the granules, this strain was excluded from further experiments.

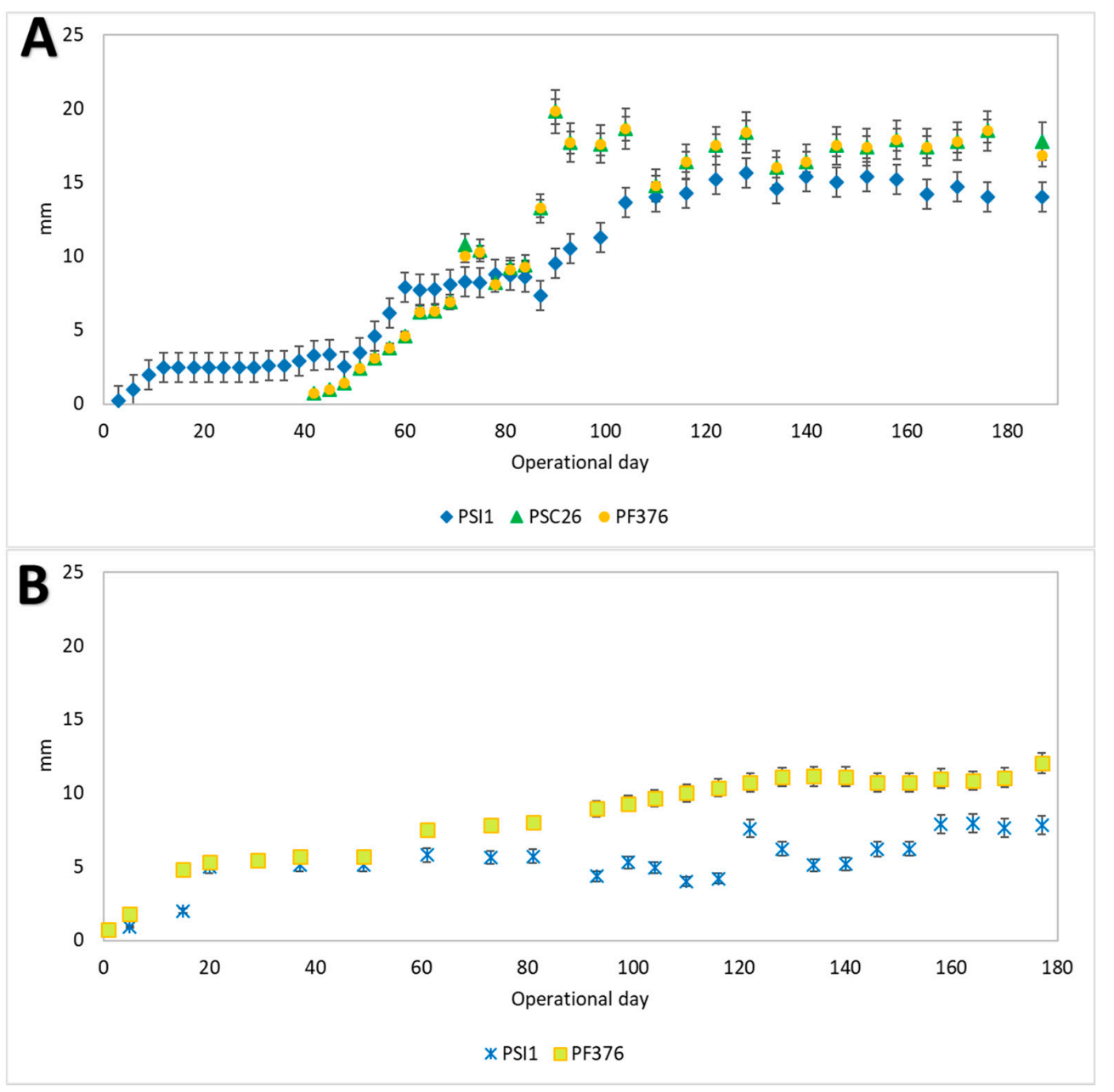

Figure 2. Mean size of granular biomass of Pseudomonas fluorescens PSC26 (PSC26), Pseudomonas fluorescens 376 (PF376), and Pseudomonas stutzeri I1 (PSI1) fed with sodium acetate (A) and methanol (B).

Unlike the P. denitrificans strain, the other strains tested in this study produced regular granules (Figure 2). Pseudomonas stutzeri I1 was the first strain to produce a core during granule formation (produced after five days of operation), with an average size of $2 \mathrm{~mm}$. The granules formed were stable during 40 days of operation, showing the excellent granulation capacity of this bacterial strain under the operational conditions applied in the experiment. After day 40 of operation, the mature granules formed by P. stutzeri I1 were highly adapted to the system, which was observed by the increase in the mean size over operational time, despite the reduction in carbon concentration. The granules were dense and compact, presenting a regular surface, regardless of their average mean size (Figure $3 \mathrm{~A}$ ). 


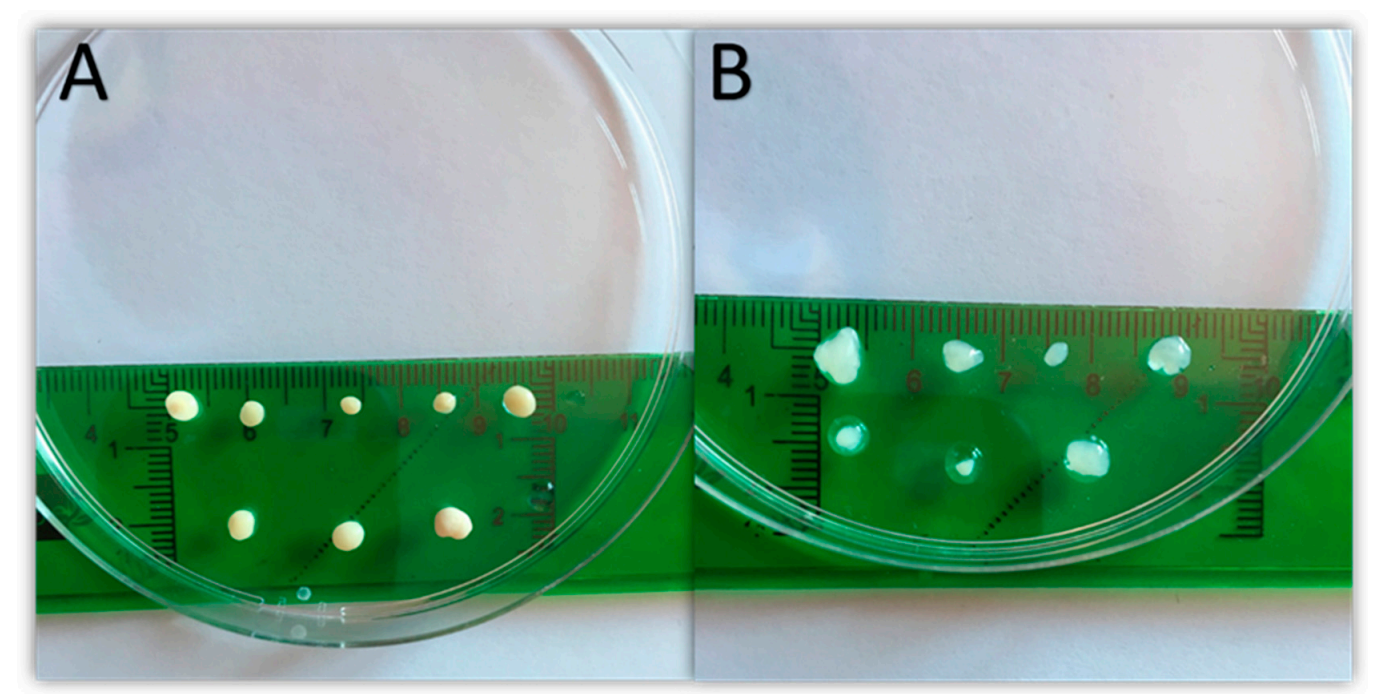

Figure 3. (A) Granules of Pseudomonas stutzeri at operational day 40; (B) granules of Pseudomonas fluorescens PSC26 at operational day 40 .

Pseudomonas fluorescens strains PSC26 and 376 showed similar trends in terms of granular conformation and average size (Figure 2). The first granules were observed at operational day 40, (Figure 3B). Once the cores of the granules formed, the average diameter of the granule increased quickly, reaching $19 \mathrm{~mm}$ after 90 days in bioreactors inoculated with P. fluorescens strains. Notably, the trend was similar for all experiments under different concentrations of sodium acetate, and a mean size from 15 to $20 \mathrm{~mm}$ was observed at operational day 120 . The granules presented a soft surface and a compact aspect throughout the experiment. A slightly higher density was observed for granules produced by P. fluorescens strain 376 than those formed by the PSC26 strain.

In order to study the ability of the denitrifying strains to form granules in the presence of other carbon sources, two bioreactors were fed with synthetic groundwater supplemented with methanol as a carbon source. The bioreactors were either inoculated with P. stutzeri I1 or P. fluorescences 376, since these two strains showed the best capacity to remove nitrogen and produce stable granular biomass (Figure 2). The granulation results showed that both strains were able to produce granules that were very similar regardless of the carbon source available in the aerobic granular systems (Figure 3), although the results indicated that the range of granular size was smaller than that of the granules cultivated with sodium acetate. The results indicate that $P$. fluorescens 376 produces granules with larger diameters than the corresponding granules produced by $P$. stutzeri I1, with average sizes of 10 and $7 \mathrm{~mm}$, respectively, after operational day 150 (Figure 4).

The settling velocity of the granules in the bioreactors fed with sodium acetate (Figure 5A) produced a decrease in decantation time, although after operational day 100, the average settling velocity of the granules did not change, regardless of the strain used. This rising trend was more pronounced for P. stutzeri I1 and P. fluorescens PSC26 than for $P$. fluorescens 376 . The fastest production of granules occurred with $P$. stutzeri I1 inoculum, coinciding with the observation of the higher density and compactness of such granules. Similar settling velocities were detected when the bioreactor was inoculated with the two strains of P. fluorescens (PF376 and PSC26), but increased firmness conformation was observed when the bioreactor was inoculated with P. fluorescens 376 (Figure 4). Pseudomonas stutzeri I1 and P. fluorescens 376 were selected as the best strains for producing granules and for nitrate removal (Figure 5B). Once the best strains for the formation of granules and nitrate removal were determined, an alternative $C$ source was used to feed the bioreactors (methanol). With the alternative carbon source, the opposite effect of using sodium acetate was observed, because the PSI1 inoculum produced granules with slower settling velocity (close to $25 \mathrm{~m} \cdot \mathrm{h}^{-1}$ ), and in the bioreactor inoculated with PF376, the granules produced presented velocities close to $60 \mathrm{~m} \cdot \mathrm{h}^{-1}$. This outcome could be caused by the strain's affinity 
and consumption advantage for the different organic carbon source [35]. These results suggest that, in general terms, the settling velocity for the granules is higher when sodium acetate is used as a carbon source compared with the same conditions but using methanol.

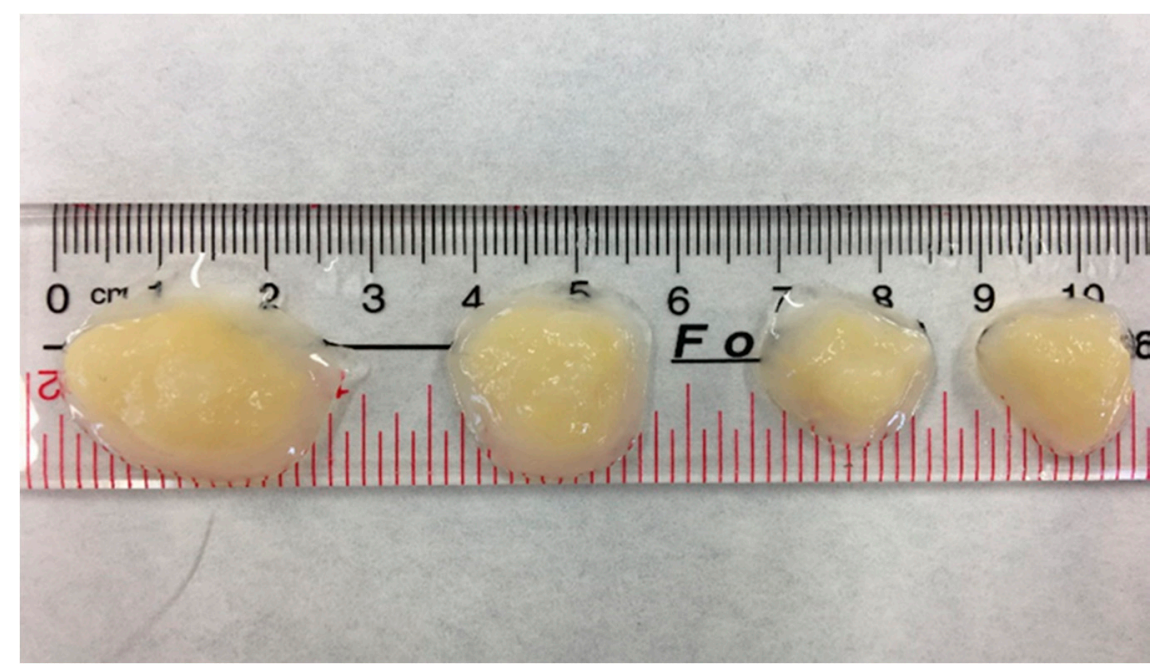

Figure 4. Mature granular biomass of Pseudomonas fluorescens 376 at operational day 150.

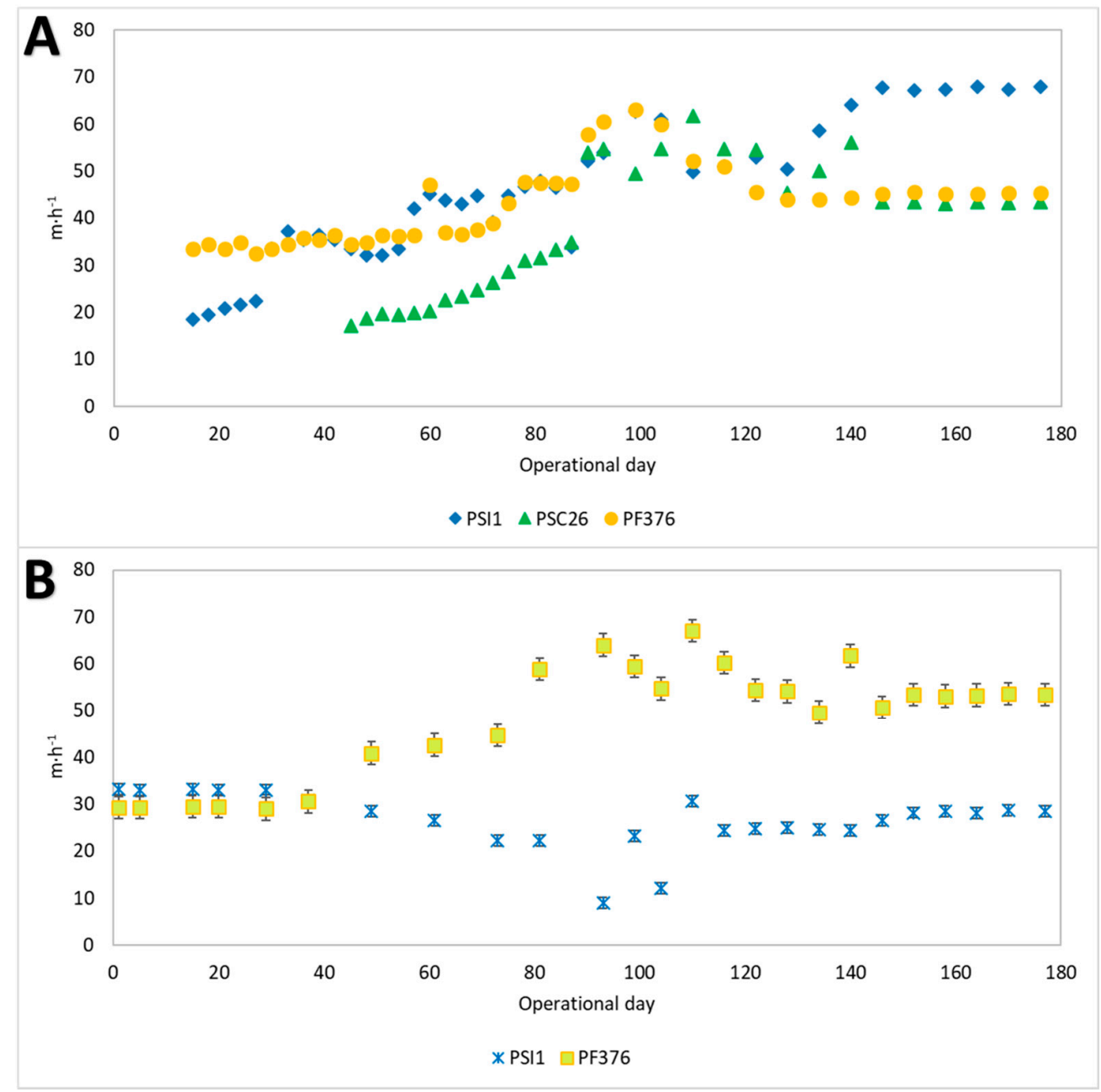

Figure 5. The settling velocity of granular biomass of Pseudomonas fluorescens PSC26 (PSC26), Pseudomonas fluorescens 376 (PF376), and Pseudomonas stutzeri I1 (PSI1) fed with sodium acetate (A) and methanol (B). 


\section{2. $\mathrm{BOD}_{5}$ and $\mathrm{COD}$ Degradation}

Organic matter removal was monitored based on the biological oxygen demand at day $5\left(\mathrm{BOD}_{5}\right)$. The $\mathrm{BOD}_{5}$ removal ratio in the different bioreactors was strongly affected by changes attributed to the composition of the influent water. A sharp decrease in $\mathrm{BOD}_{5}$ was observed at operational day 35 for all the different conditions. However, at operational day 97 , abrupt changes in the $\mathrm{BOD}_{5}$ removal ratio were recorded (Figure $6 \mathrm{~A}$ ). In this respect, the most affected bioreactors were those inoculated with cultures of P. stutzeri strain and P. fluorescens strain 376.
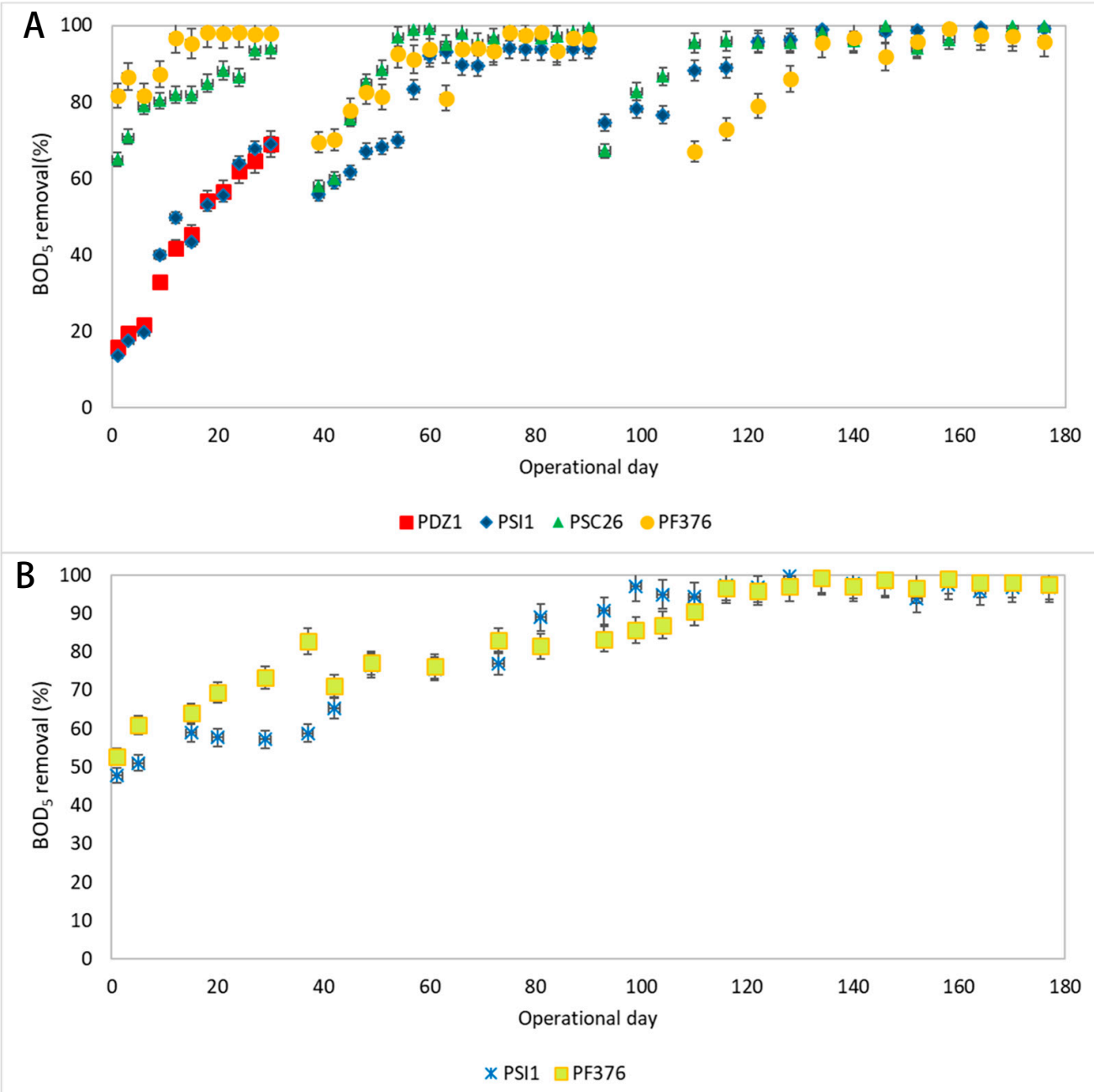

Figure 6. $\mathrm{BOD}_{5}$ removal by granular biomass for Pseudomonas fluorescens PSC26 (PSC26), Pseudomonas fluorescens 376 (PF376), Pseudomonas stutzeri I1 (PSI), and Pseudomonas denitrificans Z1 (PDZ1) fed with sodium acetate (A) and methanol (B).

When the GSBR systems were fed with methanol as a carbon source, the bioreactors inoculated with P. stutzeri and P. fluorescens 376 showed increased $\mathrm{BOD}_{5}$ removal over the operational time (Figure 6B). These results suggest that methanol and acetate are excellent carbon sources for the formation of granules and nitrate removal. Regardless of the carbon source tested in the granular systems, the consumption of organic matter was practically $100 \%$ of the concentration added to the synthetic groundwater, suggesting that nitrate removal is limited by the concentration of organic matter added. Therefore, the data obtained confirm that after treatment, the generated effluents do not contain significant amounts of organic matter, which is important for their possible use for human consumption [36]. 
The removal efficiency based on COD followed a similar trend to the removal of $\mathrm{BOD}_{5}$. Accordingly, changes in the COD responded to the carbon concentration in the influent (Figure 7A), with the highest COD removal observed in the bioreactor inoculated with $P$. fluorescens PSC26. This finding indicates that this microorganism needs a shorter period of adaptation to a new influent composition. The COD removal ratio observed in bioreactors inoculated with $P$. denitrificans increased quickly during the first days of operation, but this strain was discarded from the experiment as no granules formed in the presence of this microorganism. The COD removal observed when the systems were inoculated with $P$. stutzeri I1, P. fluorescens PSC26, and P. fluorescens followed a similar trend from operational day 60 , with a removal ratio ranging from $75 \%$ to $98 \%$. The highest removal ratios were reached at the end of operation, when the bioreactor operated under $200 \mathrm{mg} \cdot \mathrm{L}^{-1}$ sodium acetate, because the available substrate for heterotrophic denitrifiers was reduced. However, the bioreactors fed with methanol showed an increased COD removal ratio during the first 40 days (Figure 7B). COD removal ratios higher than $90 \%$ were achieved at an earlier stage using methanol than when using sodium acetate with P. stutzeri I1 and P. fluorescens 376. Therefore, the average values in the steady-stable period ranged from $75 \%$ to $95 \%$ for reactors fed with sodium and up to $90 \%$ for reactors fed with methanol.

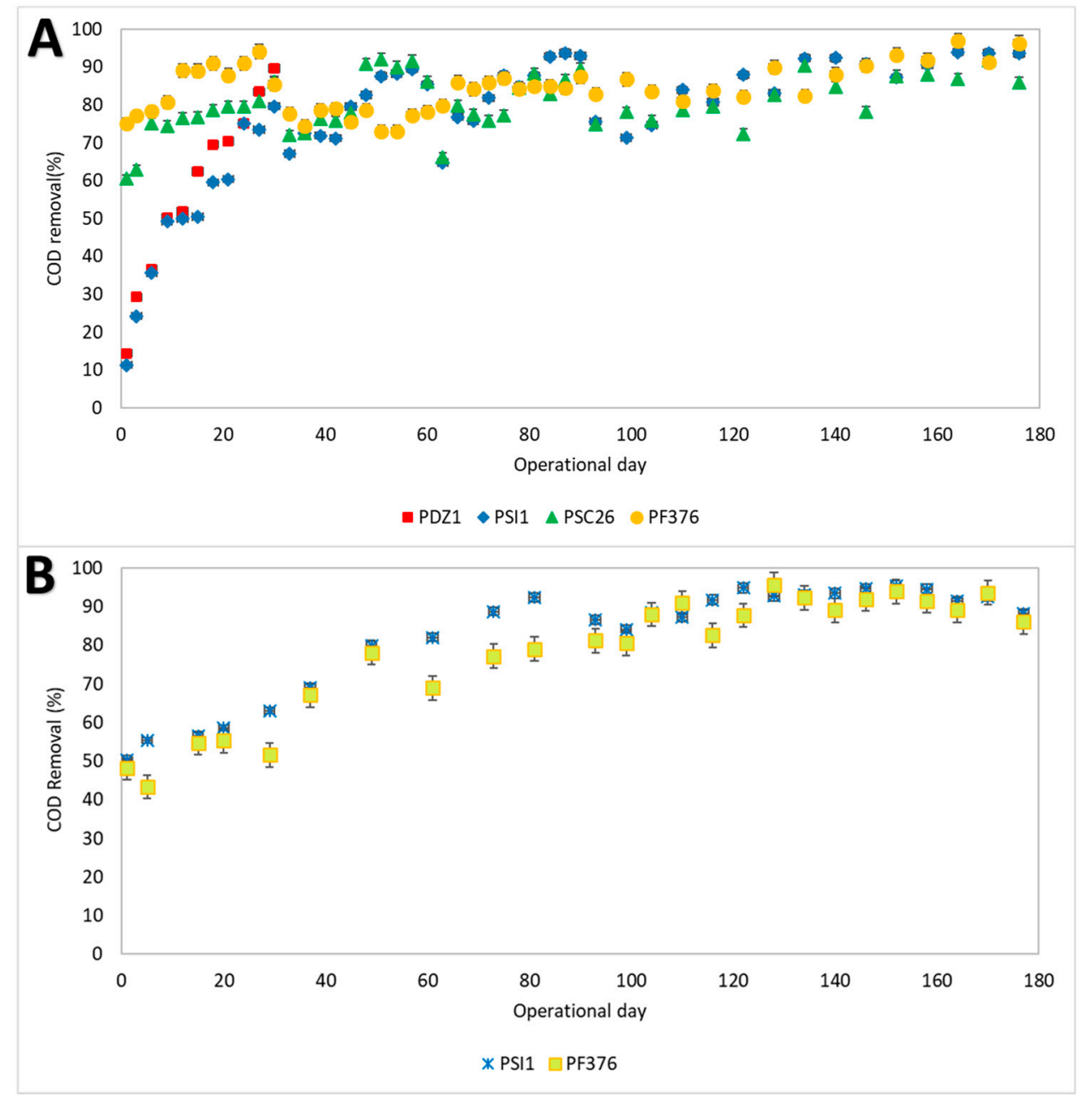

Figure 7. The COD by granular biomass for Pseudomonas fluorescens PSC26 (PSC26), Pseudomonas fluorescens 376 (PF376), Pseudomonas stutzeri I1 (PSI1), and Pseudomonas denitrificans Z1 (PDZ1) fed with sodium acetate (A) and methanol (B).

\subsection{Nitrate Removal Performance}

One of the main goals of this research was to assess the performance of the selected denitrifying strains in removing nitrate from groundwater within GSBR systems. The nitrogen 
removal capacity was studied to characterize the most efficient carbon source, and the $\mathrm{C} / \mathrm{N}$ ratio was assessed to optimize the denitrification process in GSBR systems containing granular biomass produced by Pseudomonas strains. When concentrations of sodium acetate below $400 \mathrm{mg} \cdot \mathrm{L}^{-1}$ were used in the GSBRs, a remarkable reduction was observed in the system's capacity to remove nitrate from the groundwater. Nitrate removal was around $50 \%$ when 200 to $300 \mathrm{mg} \cdot \mathrm{L}^{-1}$ sodium acetate was used, being even lower if the bioreactor was inoculated with $P$. fluorescens. It is therefore evident that a high C:N ratio is necessary for good nitrate removal performance when acetate is used as a carbon source (Figure 8A). These results confirm previous data published by Tian et al. [37], who observed that high nitrate removal capacity in biological systems was directly related to acetate concentration, indicating that a C:N ratio of approximately three to five was the most appropriate ratio to support the metabolism of heterotrophic denitrifiers [38]. Since the C:N ratio is crucial for nitrate removal from groundwater, the amount of carbon source required should be determined as a function of the level of nitrate pollution, as established by the European Water Framework [36]. Thus, the acetate concentration can be adjusted to account for the degree of groundwater contamination in the production of potable quality water. This biological system was successful in reducing the nitrate concentration from groundwater. For even higher nitrate concentration reduction, other methods based on physic-chemical processes have been proposed to reach removal values close to $90 \%$, such as those reported by Eljamal et al. [39] and Mokete et al. [40] based on the use of nanoparticles.

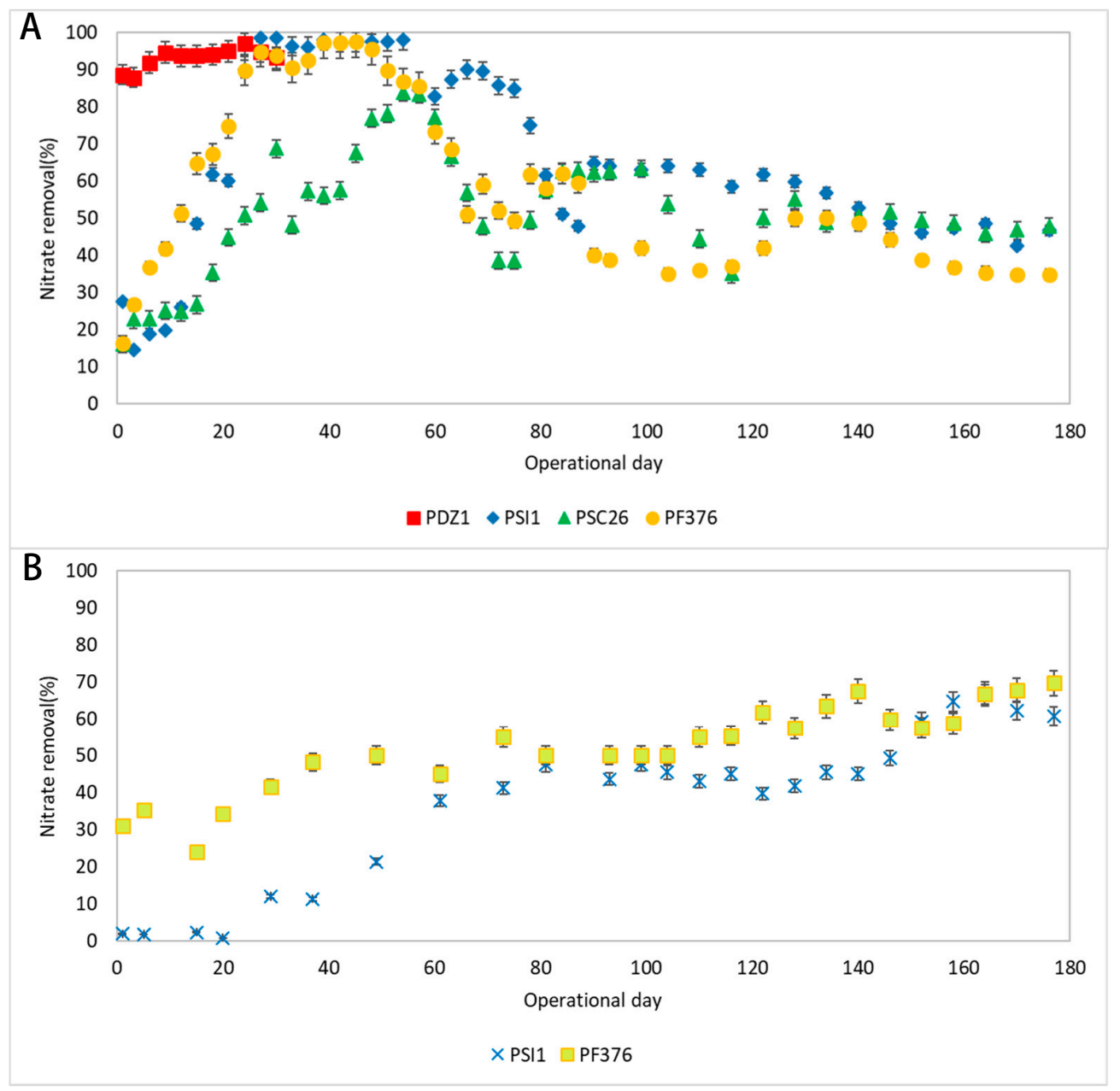

Figure 8. Nitrate removal ratio of granular biomass for Pseudomonas fluorescens PSC26 (PSC26), Pseudomonas fluorescens 376 (PF376), and Pseudomonas stutzeri I1 (PSI1) fed with sodium acetate (A) and methanol (B). 
Some differences were observed when the GSBR systems were fed with methanol (Figure $8 \mathrm{~B}$ ). The addition of methanol at concentrations of 250 and $300 \mathrm{mg} \cdot \mathrm{L}^{-1}$ resulted in efficient nitrate removal when the systems were inoculated with $P$. stutzeri and P. fluorescens strain 376, applying a C: $\mathrm{N}$ ratio close to two. In some cases, nitrate removal above $70 \%$ was observed, suggesting that denitrification occurs at lower organic matter/nitrate ratios than when acetate provides the carbon source [41]. It is possible that these yields, as in the case of acetate, can be increased with the addition of larger amounts of methanol, but if we consider that the regulations established by the European Water Framework [36], in our opinion, it is clear that methanol is an appropriate carbon source for the removal of nitrates from groundwater. Moreover, P. stutzeri strains were reported as denitrifying microorganisms under aerobic conditions [42], supporting the results observed in this research.

\subsection{Nitrogen Mass Balance over the Period of Operation}

Based on our analysis of the nitrogen mass balance (Table 2), the bioreactor inoculated with P. fluorescens PSC26 produced the lowest conversion of nitrate to nitrogen gas, regardless of operation stage, with absolute amounts ranging from 29.00 to $66.00 \mathrm{mg}-\mathrm{N} \cdot \mathrm{d}^{-1}$. In general, the most success was observed in the bioreactor with granules derived from P. fluorescens 376, followed by the bioreactor with granules derived from P. stutzeri I1. It follows that bioreactors inoculated with both strains separately presented a better transformation of nitrate to gas, and a C:N ratio close to $3-4$, suggesting that this C:N ratio results in complete denitrification. This is supported by the findings and is corroborated by other authors working in wastewater treatment plants, such as Miyahara et al. [43] and Vacková et al. [44]. Those authors drew attention to the importance of aerobic denitrification in biotechnological processes in order to reduce the emission of greenhouse gases. However, lower concentrations of carbon in the influent resulted in the reduced production of gases in this study. Moreover, it is relevant to point out that the bioreactor operating with the same $\mathrm{C}: \mathrm{N}$ ratio but using methanol as a carbon source promoted a more efficient reduction of nitrate than the bioreactor fed with acetate. Importantly, the generation of intermediate products from denitrification was not detected, as could be observed by the $\mathrm{NO}_{2}-\mathrm{N}$ in the effluent.

Although P. denitrificans Z1 was initially included in this study, the inability of this strain to form granules precluded its use as an inoculum in GSBR systems. Other strains of $P$. denitrificans could be tested in order to establish whether it is possible to use this denitrifying microorganism [29]. Our observations must be considered limited to the strains used in our study, although, based on nitrogen mass balance results, it appears that nitrate removal and the transformation of nitrate to dinitrogen gas could be easily modified by adjusting the concentration of the carbon source in the influent. Moreover, inoculation with denitrifying strains of Pseudomonas that are able to produce stable granules in GSBR systems can be considered an innovation in the treatment of groundwater contaminated with nitrate since the pollutant is removed and no nitrous oxide is released into the atmosphere as a result of this denitrification process. This process therefore represents an advance in the knowledge of biological denitrification systems driven by microorganisms, which encourages the complete reduction of nitrate to dinitrogen gas [45]. To the best of our knowledge, for the first time, this study describes the use of cultures of denitrifying strains containing the nos $Z$ gene for the treatment of groundwater polluted with nitrates. Therefore, this study is important from a technical point of view, in addition to its environmental significance. A potential application of this technology is the addition of mature granules of Pseudomonas to AGS systems for treating polluted groundwater [1], with the aim of encouraging the presence of denitrifying bacteria carrying the nos $Z$ gene. 


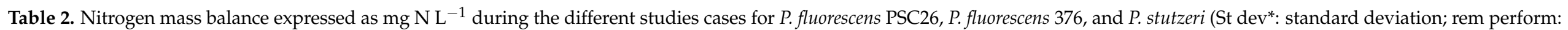
removal performance) $P$. denitrificans was not included due to not achieving granulation.

\begin{tabular}{|c|c|c|c|c|c|c|c|c|c|}
\hline Strain & & Phase & $\mathbf{T N}_{\text {in }}$ & $\mathrm{TN}_{\text {out }}$ & $\mathrm{NO}_{3}-\mathrm{N}_{\mathrm{in}}$ & $\mathrm{NO}_{3}-\mathrm{N}_{\text {out }}$ & $\mathrm{NO}_{2}-\mathrm{N}_{\text {out }}$ & $\mathrm{NO}, \mathrm{N}_{2} \mathrm{O}, \mathrm{N}_{2}$ Gas & Rem Perform (\%) \\
\hline \multirow{6}{*}{ P. fluorescens PSC26 } & \multirow{6}{*}{$\mathrm{NaAc}: \mathrm{NaNO}_{3}$} & $900: 127$ & 130.75 & 88.32 & 130.75 & 88.27 & 0.05 & 42.44 & 32.45 \\
\hline & & $400: 127$ & 130.75 & 23.50 & 130.75 & 23.50 & 0.00 & 107.25 & 82.02 \\
\hline & & $300: 100$ & 102.95 & 53.28 & 102.95 & 53.25 & 0.03 & 49.67 & 48.25 \\
\hline & & 200:100 & 102.95 & 37.80 & 102.95 & 37.79 & 0.00 & 65.16 & 63.29 \\
\hline & & Average & 116.85 & 50.72 & 116.85 & 50.70 & 0.02 & 66.13 & \\
\hline & & St dev. & 16.05 & 27.85 & 16.05 & 27.83 & 0.02 & 29.00 & \\
\hline \multirow{8}{*}{ P. fluorescens 376} & \multirow{4}{*}{$\mathrm{NaAc}: \mathrm{NaNO}_{3}$} & $900: 127$ & 130.75 & 14.11 & 130.75 & 14.11 & 0.00 & 116.64 & 89.21 \\
\hline & & $400: 127$ & 130.75 & 20.31 & 130.75 & 20.31 & 0.00 & 110.44 & 84.46 \\
\hline & & $300: 100$ & 102.95 & 37.79 & 102.95 & 37.79 & 0.00 & 65.16 & 63.29 \\
\hline & & $200: 100$ & 102.95 & 44.50 & 102.95 & 44.50 & 0.00 & 58.45 & 56.78 \\
\hline & \multirow{4}{*}{$\mathrm{CH}_{3} \mathrm{OH}: \mathrm{NaNO}_{3}$} & $300: 100$ & 102.95 & 63.51 & 102.95 & 63.51 & 0.00 & 39.44 & 38.31 \\
\hline & & 200:100 & 102.95 & 35.59 & 102.95 & 35.59 & 0.00 & 67.36 & 65.43 \\
\hline & & Average & 112.22 & 35.97 & 112.22 & 35.97 & 0.00 & 76.25 & \\
\hline & & St dev. & 14.35 & 17.65 & 14.35 & 17.65 & 0.00 & 30.57 & \\
\hline \multirow{6}{*}{ P. stutzeri } & \multirow{4}{*}{$\mathrm{NaAc}: \mathrm{NaNO}_{3}$} & $900: 127$ & 130.75 & 4.39 & 130.75 & 4.34 & 0.05 & 126.36 & 96.64 \\
\hline & & $400: 127$ & 130.75 & 24.16 & 130.75 & 24.16 & 0.00 & 106.59 & 81.52 \\
\hline & & $300: 100$ & 102.95 & 49.74 & 102.95 & 49.73 & 0.00 & 53.22 & 51.69 \\
\hline & & 200:100 & 102.95 & 34.79 & 102.95 & 34.79 & 0.00 & 68.16 & 66.21 \\
\hline & \multirow{2}{*}{$\mathrm{CH}_{3} \mathrm{OH}:_{\mathrm{NaNO} 3}$} & Average & 112.22 & 34.34 & 112.22 & 34.33 & 0.01 & 77.88 & \\
\hline & & St dev. & 13.10 & 17.35 & 13.10 & 17.36 & 0.02 & 29.06 & \\
\hline
\end{tabular}




\section{Conclusions}

The aerobic granular technology inoculated with denitrifying bacteria showed a success nitrate removal ratio. which depends on the carbon concentration added to the influent. The findings showed that denitrifying Pseudomonas strains are able to produce stable granules in GSBR systems. resulting in high nitrate removal. Moreover. the denitrification process can be efficiently performed with different carbon sources such as acetate and methanol. Therefore. inoculation and enrichment of GSBR systems with culture of selected denitrifying Pseudomonas strains carrying the nosZ gene may be considered as an innovative alternative in order to improve AGS technology. The results obtained about nitrate removal using identifying granular biomass provide deeper knowledge about the granular formation and denitrification process within granules in systems implemented for the treatment of polluted groundwater. Biological denitrification can be considered an environmentally friendly alternative since no greenhouse gases are produced during the denitrification process.

Author Contributions: M.H.-M. methodology; B.M.-P. data curation. methodology. formal analysis; software. writing-original draft preparation; J.G.-L. reviewing and editing: financial support; experimental design; M.M. reviewing and editing; A.G.-M. reviewing and editing. All authors have read and agreed to the published version of the manuscript.

Funding: This research was funded by LIFE16 ENV/ES/000196 project.

Institutional Review Board Statement: Not applicable.

Informed Consent Statement: Not applicable.

Acknowledgments: The authors would like to acknowledge the support provided by the Institute of Water Research of University of Granada. Spain; the Zaidin Experimental station (CSIC. Granada); and the funding proving by LIFE16 ENV/ES/000196 and by the Andalusian Regional Government and the European Union under the reserarch project CV20-01559, and the support of research project CV20-01159.

Conflicts of Interest: The authors declare no conflict of interest.

\section{References}

1. Mohseni-Bandpi, A.; Elliott, D.J.; Zazouli, M.A. Biological nitrate removal processes from drinking water supply-a review. J. Environ. Health Sci. Eng. 2013, 11, 35. [CrossRef] [PubMed]

2. Rezvani, F.; Sarrafzadeh, M.-H.; Ebrahimi, S.; Oh, H.-M. Nitrate removal from drinking water with a focus on biological methods: A review. Environ. Sci. Pollut. Res. 2019, 26, 1124-1141. [CrossRef] [PubMed]

3. Hurtado-Martinez, M.; Muñoz-Palazon, B.; Robles-Arenas, V.M.; Gonzalez-Martinez, A.; Gonzalez-Lopez, J. Biological nitrate removal from groundwater by an aerobic granular technology to supply drinking water at pilot-scale. J. Water Process. Eng. 2021, 40, 101786. [CrossRef]

4. Coss, A.; Cantor, K.P.; Reif, J.S.; Lynch, C.F.; Ward, M.H. Pancreatic Cancer and Drinking Water and Dietary Sources of Nitrate and Nitrite. Am. J. Epidemiol. 2004, 159, 693-701. [CrossRef] [PubMed]

5. Ward, M.H.; Jones, R.R.; Brender, J.D.; De Kok, T.M.; Weyer, P.J.; Nolan, B.T.; Villanueva, C.M.; Van Breda, S.G. Drinking Water Nitrate and Human Health: An Updated Review. Int. J. Environ. Res. Public Health 2018, 15, 1557. [CrossRef] [PubMed]

6. Brender, J.D.; Weyer, P.J.; Romitti, P.A.; Mohanty, B.P.; Shinde, M.U.; Vuong, A.M.; Huber, J.C., Jr. Prenatal nitrate intake from drinking water and selected birth defects in offspring of participants in the national birth defects prevention study. Environ. Health Perspect. 2013, 121, 1083-1089. [CrossRef] [PubMed]

7. European Environment Agency (EEA). Groundwater Nitrate. Available online: www.eea.europa.eu/: (accessed on 4 December 2020).

8. European Union (EU). Council Directive 91/676/EEC of 12 December 1991 Concerning the Protection of Waters against Pollution Caused by Nitrates from Agricultural Sources; European Union (EU): Brussels, Belgium, 1991.

9. Vitoria, I.; Maraver, F.; Sanchez-Valverde, F.; Armijo, F. Nitrate concentrations in tap water in Spain. Gac. Sanit. 2015, 29, 217. [CrossRef]

10. Eljamal, R.; Eljamal, O.; Maamoun, I.; Yilmaz, G.; Sugihara, Y. Enhancing the characteristics and reactivity of nZVI: Polymers effect and mechanisms. J. Mol. Liq. 2020, 315, 113714. [CrossRef]

11. Martínez, J.; Ortiz, A.; Ortiz, I. State-of-the-art and perspectives of the catalytic and electrocatalytic reduction of aqueous nitrates. Appl. Catal. B Environ. 2017, 207, 42-59. [CrossRef] 
12. Wang, L.; Chen, A.S.; Wang, A.; Condit, W.E.; Battelle, C.; Sorg, T.J.; Supply, W. Arsenic and Nitrate Removal from Drinking Water by Ion Exchange US EPA Demonstration Project at Vale. OR Final Performance Evaluation Report; National Risk Management Research Laboratory: Cincinnati, OH, USA, 2011.

13. Adeleye, A.S.; Conway, J.R.; Garner, K.; Huang, Y.; Su, Y.; Keller, A.A. Engineered nanomaterials for water treatment and remediation: Costs. benefits. and applicability. Chem. Eng. J. 2016, 286, 640-662. [CrossRef]

14. Epsztein, R.; Nir, O.; Lahav, O.; Green, M. Selective nitrate removal from groundwater using a hybrid nanofiltration-reverse osmosis filtration scheme. Chem. Eng. J. 2015, 279, 372-378. [CrossRef]

15. Zeng, H.; Yin, C.; Zhang, J.; Li, D. Start-Up of a Biofilter in a Full-Scale Groundwater Treatment Plant for Iron and Manganese Removal. Int. J. Environ. Res. Public Health 2019, 16, 698. [CrossRef] [PubMed]

16. Pirsaheb, M.; Khosravi, T.; Sharafi, K.; Mouradi, M. Comparing operational cost and performance evaluation of electrodialysis and reverse osmosis systems in nitrate removal from drinking water in Golshahr. Mashhad. Desalin. Water Treat. 2015, 57, 5391-5397. [CrossRef]

17. Ahmed, M.B.; Zhou, J.L.; Ngo, H.H.; Guo, W.; Thomaidis, N.S.; Xu, J. Progress in the biological and chemical treatment technologies for emerging contaminant removal from wastewater: A critical review. J. Hazard. Mater. 2017, 323, 274-298. [CrossRef]

18. Panepinto, D.; Genon, G.; Borsarelli, A. Improvement of nitrogen removal in a large municipal wastewater plant. Chem. Eng. Trans. 2013, 34, 67-72.

19. Corsino, S.F.; Capodici, M.; Di Pippo, F.; Tandoi, V.; Torregrossa, M. Comparison between kinetics of autochthonous marine bacteria in activated sludge and granular sludge systems at different salinity and SRTs. Water Res. 2019, 148, 425-437. [CrossRef] [PubMed]

20. Nancharaiah, Y.; Reddy, G.K.K. Aerobic granular sludge technology: Mechanisms of granulation and biotechnological applications. Bioresour. Technol. 2018, 247, 1128-1143. [CrossRef] [PubMed]

21. Rusanowska, P.; Cydzik-Kwiatkowska, A.; Świątczak, P.; Wojnowska-Baryła, I. Changes in extracellular polymeric substances (EPS) content and composition in aerobic granule size-fractions during reactor cycles at different organic loads. Bioresour. Technol. 2019, 272, 188-193. [CrossRef]

22. Eljamal, R.; Kahraman, I.; Eljamal, O.; Thompson, I.P.; Maamoun, I.; Yilmaz, G. Impact of nZVI on the formation of aerobic granules. bacterial growth and nutrient removal using aerobic sequencing batch reactor. Environ. Technol. Innov. 2020, $19,100911$. [CrossRef]

23. Lycus, P.; Soriano-Laguna, M.J.; Kjos, M.; Richardson, D.J.; Gates, A.J.; Milligan, D.A.; Frostegård, Å.; Bergaust, L.; Bakken, L.R. A bet-hedging strategy for denitrifying bacteria curtails their release of N2O. Proc. Natl. Acad. Sci. USA 2018, 115, 11820-11825. [CrossRef]

24. Muñoz-Palazon, B.; Rodriguez-Sanchez, A.; Hurtado-Martinez, M.; Santana, F.; Gonzalez-Lopez, J.; Mack, L.; Gonzalez-Martinez, A. Polar Arctic Circle biomass enhances performance and stability of aerobic granular sludge systems operated under different temperatures. Bioresour. Technol. 2020, 300, 122650. [CrossRef]

25. Wu, L.; Peng, L.; Wei, W.; Wang, D.; Ni, B.-J. Nitrous oxide production from wastewater treatment: The potential as energy resource rather than potent greenhouse gas. J. Hazard. Mater. 2020, 387, 121694. [CrossRef]

26. Du, R.; Peng, Y.; Cao, S.; Li, B.; Wang, S.; Niu, M. Mechanisms and microbial structure of partial denitrification with high nitrite accumulation. Appl. Microbiol. Biotechnol. 2016, 100, 2011-2021. [CrossRef]

27. Andrade, G.; Esteban, E.; Velasco, L.; Lorite, M.J.; Bedmar, E.J. Isolation and identification of N2-fixing microorganisms from the rhizosphere of Capparis spinosa (L.). Plant Soil 1997, 197, 19-23. [CrossRef]

28. Wragg, J.; Harrison, H.; West, J.M.; Yoshikawa, H. Comparison of microbiological influences on the transport properties of intact mudstone and sandstone and its relevance to the geological disposal of radioactive waste. Miner. Mag. 2012, 76, 3251-3259. [CrossRef]

29. Chen, Z.; Jiang, Y.; Chang, Z.; Wang, J.; Song, X.; Huang, Z.; Chen, S.; Li, J. Denitrification characteristics and pathways of a facultative anaerobic denitrifying strain. Pseudomonas denitrificans G1. J. Biosci. Bioeng. 2020, 129, 715-722. [CrossRef] [PubMed]

30. Muñoz-Palazon, B.; Rodriguez-Sanchez, A.; Hurtado-Martinez, M.; Gonzalez-Lopez, J.; Pfetzing, P.; Gonzalez-Martinez, A. Performance and microbial community structure of aerobic granular bioreactors at different operational temperature. J. Water Process. Eng. 2020, 33, 101110. [CrossRef]

31. Laguna, A.; Ouattara, A.; Gonzalez, R.O.; Baron, O.; Fama, G.; El Mamouni, R.; Macarie, H. A simple and low cost technique for determining the granulometry of upflow anaerobic sludge blanket reactor sludge. Water Sci. Technol. 1999, 40, 1-8. [CrossRef]

32. American Public Health Association. APHA Standard Methods for the Examination of Water and Wastewatern, 21st ed.; APHAAWWWA-WEF: Washington, DC, USA, 2012.

33. González-Martínez, A.; Calderón, K.; Albuquerque, A.; Hontoria, E.; González-López, J.; Guisado, I.M.; Osorio, F. Biological and technical study of a partial-SHARON reactor at laboratory scale: Effect of hydraulic retention time. Bioprocess Biosyst. Eng. 2012, 36, 173-184. [CrossRef] [PubMed]

34. Rodriguez-Sanchez, A.; Muñoz-Palazon, B.; Hurtado-Martinez, M.; Mikola, A.; Gonzalez-Lopez, J.; Vahala, R.; Gonzalez-Martinez, A. Analysis of microbial communities involved in organic matter and nitrogen removal in a full-scale moving bed biofilm reactor located near the Polar Arctic Circle. Int. Biodeterior. Biodegrad. 2020, 146, 104830. [CrossRef] 
35. Wisniewski, K.; Kowalski, M.; Makinia, J. Modeling nitrous oxide production by a denitrifying-enhanced biologically phosphorus removing (EBPR) activated sludge in the presence of different carbon sources and electron acceptors. Water Res. 2018, 142, 55-64. [CrossRef]

36. Directive, W.F. Water Framework Directive. J. Ref. OJL 2000, 327, 1-73.

37. Tian, T.; Yu, H.-Q. Denitrification with non-organic electron donor for treating low $\mathrm{C} / \mathrm{N}$ ratio wastewaters. Bioresour. Technol. 2020, 299, 122686. [CrossRef] [PubMed]

38. Eljamal, O.; Jinno, K.; Hosokawa, T. Denitrification of secondary wastewater using sawdust. Mem. Fac. Eng. 2006, 66, 115-128.

39. Mokete, R.; Eljamal, O.; Sugihara, Y. Exploration of the reactivity of nanoscale zero-valent iron (NZVI) associated nanoparticles in diverse experimental conditions. Chem. Eng. Process. Process. Intensif. 2020, 150, 107879. [CrossRef]

40. He, Y.; Wang, Y.; Song, X. High-effective denitrification of low C/N wastewater by combined constructed wetland and biofilmelectrode reactor (CW-BER). Bioresour. Technol. 2016, 203, 245-251. [CrossRef]

41. Yang, X.; Wang, S.; Zhou, L. Effect of carbon source. C/N ratio. nitrate and dissolved oxygen concentration on nitrite and ammonium production from denitrification process by Pseudomonas stutzeri D6. Bioresour. Technol. 2012, 104, 65-72. [CrossRef] [PubMed]

42. Sun, Y.; Feng, L.; Li, A.; Zhang, X.; Yang, J.; Ma, F. Ammonium assimilation: An important accessory during aerobic denitrification of Pseudomonas stutzeri T13. Bioresour. Technol. 2017, 234, 264-272. [CrossRef]

43. Miyahara, M.; Kim, S.-W.; Fushinobu, S.; Takaki, K.; Yamada, T.; Watanabe, A.; Miyauchi, K.; Endo, G.; Wakagi, T.; Shoun, H. Potential of Aerobic Denitrification by Pseudomonas stutzeri TR2 To Reduce Nitrous Oxide Emissions from Wastewater Treatment Plants. Appl. Environ. Microbiol. 2010, 76, 4619-4625. [CrossRef]

44. Vacková, L.; Srb, M.; Stloukal, R.; Wanner, J. Comparison of denitrification at low temperature using encapsulated Paracoccus denitrificans. Pseudomonas fluorescens and mixed culture. Bioresour. Technol. 2011, 102, 4661-4666. [CrossRef]

45. Hallin, S.; Philippot, L.; Löffler, F.E.; Sanford, R.A.; Jones, C.M. Genomics and Ecology of Novel N2O-Reducing Microorganisms. Trends Microbiol. 2018, 26, 43-55. [CrossRef] [PubMed] 